\title{
Role of cardiopulmonary stress testing in heart failure management
}

\author{
Nandini Nair MD PhD, Enrique Gongora MD
}

\section{INTRODUCTION}

Heart failure (HF) is a global problem of epidemic proportions. In the United States HF affects more than 5 million people currently, with 500,000 newly diagnosed cases every year. It is a syndrome of multiple etiologies and can involve systolic and/ or diastolic dysfunction. The risk of death due to HF has increased partly because advances in technology have decreased the age-adjusted death rates for cardiac diseases, especially those of ischemic origin, and, therefore, increased the prevalence of HF through longer survival.

Direct measurement of ventilation and gas exchange during exercise is called a cardiopulmonary stress test (CPX). Cardiopulmonary stress testing measures multiple parameters that vary with alterations in cardiac and pulmonary function. The most important variables are expiratory ventilation (V்), pulmonary gas exchange expressed as oxygen uptake $\left(\dot{\mathrm{V}} \mathrm{O}_{2}\right)$, carbon dioxide output $\left(\dot{\mathrm{V}} \mathrm{CO}_{2}\right)$, cardiac rate and rhythm, and blood pressure. A composite set of variables measured by CPX links cardiovascular and pulmonary responses to the metabolic demands of exercise. Exercise intolerance is a characteristic feature of HF with symptoms, such as shortness of breath, fatigue, or both, which are usually out of proportion to the level of exertion. Therefore, the assessment of exercise intolerance can be used to predict the degree of cardiac impairment, stratify risk, and optimize therapy.

The use of CPX in HF patients began with the

Cooresponding Author: Nandini Nair MD PhD Author Contact Information: Nandini.nair@ttuhsc.edu DOI: 10.12746/swrccc2016.0415.207 classic investigation by Mancini et al in 1991. ' Currently, CPX is used for diagnosis, risk stratification, and prognostication (Figure 1$)^{1-5}$ This review focuses on use of CPX in the assessment of disease severity and clinical management of HF with reduced ejection fraction (HFrEF) as well as preserved ejection fraction (HFpEF).

\section{ASSESSMENT OF DISEASE SEVERITY, RISK STRATIFICATION, AND PROGNOSTI- CATION}

In HFrEF the most important use of CPX is to triage patients at the appropriate time to advanced HF therapies, such as implantation of ventricular assist devices (VADs) and cardiac transplantation. In HFpEF it is used to determine disease severity by unmasking symptoms with exercise. In both cases it is also used to guide management toward optimal medical regimens or to triage to advanced surgical therapies for HF.

The New York Heart Association (NYHA) functional class is a subjective classification addressing a patient's functional capacity. ${ }^{6}$ To overcome the subjectivity of this classification exercise testing, such as CPX, has been used to make objective decisions about the treatment of chronic HF. ${ }^{7}$ Peak oxygen consumption $\left(\mathrm{V}_{2}\right)$ has been shown to correlate with functional capacity and mortality. This relationship between oxygen consumption and outcomes was first reported by Mancini et al. ${ }^{1}$ More recently, other measurements obtained during metabolic exercise tests have been shown to predict mortality in patients with end stage HF. The slope of the relationship between ventilation and carbon dioxide production ( $\mathrm{VE} / \dot{\mathrm{V}} \mathrm{CO}_{2}$ slope), the end tidal carbon dioxide $\left(\mathrm{CO}_{2}\right)$, the oxygen uptake efficiency slope (OUES), and the rate of heart 
Figure 1 Uses of Cardiopulmonary Stress Tests in Heart failure

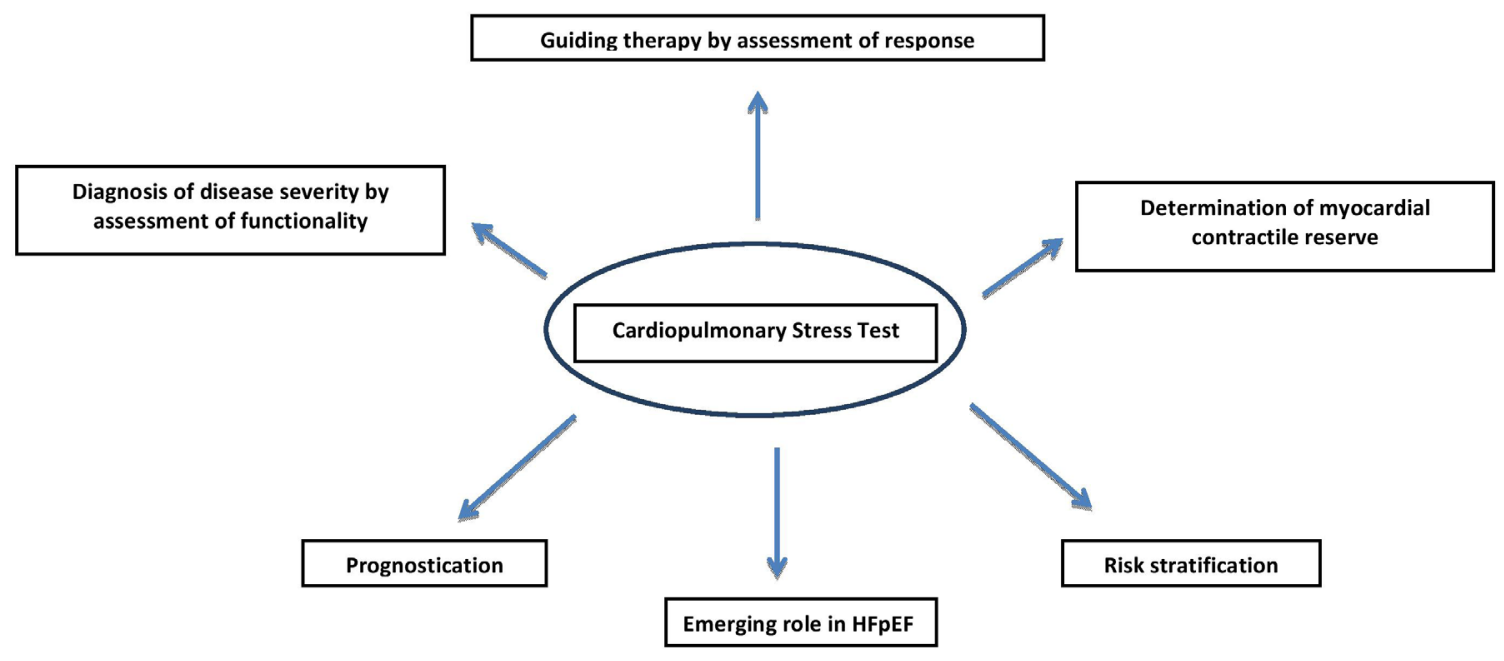

rate recovery have all been found to be useful predictors of outcome. ${ }^{8-10}$ Russell et al showed that the NYHA functional class predicts exercise parameters and can be used for assessing disease severity and outcomes. ${ }^{11}$ The study by Russell also demonstrated that there is a significant difference in the peak $\dot{\mathrm{V}}_{2}$, $\dot{\mathrm{VE}} / \dot{\mathrm{V}} \mathrm{CO}_{2}$ slope, and exercise time in patients with NYHA functional class II symptoms compared to those with NYHA functional class III/IV symptoms.

In the era of evidence-based medicine, risk stratification using multivariable scores has reliable, robust scores using CPX as one of the parameters. ${ }^{15-22}$

The Heart Failure Survival Score by Aaronson et al has proved to be better than using peak oxygen consumption alone. ${ }^{18}$ The score by Myers et $a l^{16,17}$ also used $\dot{\mathrm{V}} \mathrm{O}_{2}, \dot{\mathrm{V}} \mathrm{E} / \dot{\mathrm{V}} \mathrm{CO}_{2}$ slope, end-tidal $\mathrm{CO}_{2}$ pressure, OUES, and heart rate recovery. The $\dot{\mathrm{VE}} / \dot{\mathrm{V}} \mathrm{CO}_{2}$ slope was the strongest predictor of cardiovascular risk for mortality. Poor ventilatory control in heart failure can manifest as a crescendo-decrescendo pattern without interposed apnea called exercise oscillatory ventilation (EOV). Peak circulatory power is the product of peak $\dot{\mathrm{VO}}_{2}$ and peak systolic blood pressure. Therefore addition of these extra parameters such as Exercise Oscillatory Ventilation (EOV), the lowest $\dot{V}$ / $\dot{\mathrm{V}} \mathrm{CO}_{2}$ ratio, peak circulatory power, $\dot{\mathrm{V}} / \mathrm{V} \mathrm{VO}_{2}$ slope, and OUES, produced an optimal score for predicting the risk for mortality in this population. ${ }^{23,24}$

Exercise ventilatory power (EVP) is the ratio between peak systolic blood pressure and the VE/ $\dot{\mathrm{V} C O}{ }^{2}$ slope. Forman et $\mathrm{al}^{25}$ showed that using $\leq 3.5$ $\mathrm{mmHg}$ for the EVP as a cutoff for high risk had better prognostic discrimination capability and predict survival. Subsequently, Borghi-Silva et al $\left.\right|^{26}$ used Doppler echocardiographic recordings throughout the CPX tests in patients with HFrEF and showed that lower EVPs indicated severely impaired peak $\mathrm{V}_{2}$ and cardiac output response to exercise with consequent impairment of right heart function and hemodynamics affecting the pulmonary system. This result showed that a lower EVP indicated increased disease severity.

The relative increase in $\mathrm{V}_{2}$ to maximal work 
rate (WR) (change in $\mathrm{V}_{2}$ /change in WR) has been proposed as an indicator of cardiac efficiency and aerobic generation of adenosine triphosphate. In normal subjects this increases linearly and represents a surrogate index of cardiac output. In ventricular dysfunction during exercise, this parameter may plateau and fail to reach a value $\geq 10 \mathrm{~mL} / \mathrm{min} / \mathrm{W}$. Additionally, a flat $\Delta \dot{V}_{2} / \Delta W R$ was associated with increased systolic pulmonary artery pressure and decreased RV systolic function.

The Exertional Oscillatory Ventilation (EOV) has been found to be an important prognostic index in HF. The pathophysiological mechanisms of EOV are still not fully understood. Several factors, including decreased cardiac output, suboptimal chemoreceptor responses, reduced ventilator control, RV dysfunction, abnormal pulmonary hemodynamics, and delayed information transfer related to arterial $\mathrm{CO}_{2}$ levels from the pulmonary capillaries to peripheral and central chemoreceptors secondary to impaired ventricular function, probably affect the EOV. Hence, the addition of EOV to CPX parameters would be useful for better risk stratification and prognostication. The utilization of the Metabolic Exercise test data combined with Cardiac and Kidney Indexes (MECKI) score for prognostication helps identify cardiovascular mortality and the requirement of heart transplantation. The MECKI score consists of six laboratory values, such as hemoglobin, sodium, creatinine clearance calculated by the Modification of Diet in Renal Disease (MDRD) equation, the left ventricle ejection fraction (LVEF), the percentage of $\dot{V}_{2}$ max, and the $\dot{\mathrm{VE}} / \mathrm{VCO}_{2}$ slope.

Respiratory muscle performance (RMP) has emerged to be an important factor in risk stratifying patients with chronic HF. The strong association of RMP to indices of pulmonary vascular hemodynamics is valuable in the context of a plateau in change in $\mathrm{V}_{2}$ /change in WR. However, measurement of RMP has limitations. Despite these challenges RMP still appears to have a role in patients with HF for diagnosis, prognosis, and therapy.

\section{DETERMINATION OF MYOCARDIAL CON- TRACTILE RESERVE}

The strongest correlation with $\mathrm{V}_{2}$ max was with the peak left ventricular systolic tissue velocity (S') during exercise. Resting echocardiographic parameters, like the ejection fraction of the left ventricle, correlated poorly with exercise capacity. In idiopathic dilated cardiomyopathy, $\dot{\mathrm{V}}_{2}$ max reflected myocardial contractile reserve in ambulatory patients. However, the slope of $\dot{\mathrm{V}} / \dot{\mathrm{V}}_{\mathrm{CO}}$ was not useful in this population. In another study with non- ischemic cardiomyopathy patients, BNP and left ventricular inotropic reserve correlated well with $\mathrm{CPX}$.

\section{USE OF CPX FOR GUIDING THERAPY}

The use of CPX in HFrEF and HFpEF is well documented in the current literature. Some representative studies are listed in Table 1. The use of CPX has been demonstrated in both patients with HFrEF and those with HFpEF to help with risk stratification and prognostication. Figure 2 shows a suggested algorithm for using CPX to risk stratify and guide management of HF.

The Ventilatory Threshold (VT), also called the anaerobic threshold, assesses exercise intensity, ventilation, and metabolism and has potential use in therapeutic interventions. In HF, aerobic exercise training should be performed below the VT. Intermittently, exercise above VT can be done but with caution. $^{51,52}$ Hence assessment of VT can be used to determine exercise prescriptions in HF. In a small study CPX guided exercise rehabilitation was safe and effective for patients with $\mathrm{HF}^{53}$

\section{SUMMARY}

Cardiopulmonary exercise testing has evolved considerably since the first report of its use in HF in 1991. The test has multiple uses in HF, including defining right ventricular failure and secondary pulmonary hypertension. ${ }^{54-56}$ Multiple small studies have demonstrated the utility of CPX in diagnosis, risk stratifica- 
tion for mortality, and prognostication of HFrEF and HFpEF The use of CPX in grading diastolic dysfunction has been reported in a small study of individuals with HFpEF. ${ }^{57}$ Future research investigations may be needed to conclusively include the newer parameters discussed (EOV, OUES, EVP and circulatory power) before these can be used routinely in CPX assessments. ${ }^{58} \mathrm{CPX}$ is, therefore, a highly useful, comprehensive test to evaluate, risk stratify, and guide therapy in the present day management of HF.
Author Affiliation: Nandini Nair is a transplant cardiologist in the Department of Internal Medicine/Division of Cardiology at Texas Tech University Health Sciences Center in Lubbock, TX. Enrique Gongora is a cardiothoracic /transplant surgeon at Memorial Cardiac and Vascular Institute in Hollywood, FL.

Received: 03/10/2015

Accepted: 06/18/2016

Reviewers: Aliakbar Arvandi MD

Published electronically: 07/15/2016

Conflict of Interest Disclosures: None

Keywords: Cardiopulmonary stress test, HFpEF, HFrEF, $\dot{\mathrm{VO}}_{2} \max , \dot{\mathrm{V}} \mathrm{E} / \mathrm{V} \mathrm{CO}_{2}$

Table 1 : Selected studies investigating utility of CPX in HFrEF and HFpEF

\begin{tabular}{|c|c|c|c|c|}
\hline Study & Study Type & Type of HF & $\begin{array}{l}\text { Subjects } \\
\text { (n) }\end{array}$ & Conclusions \\
\hline $\begin{array}{l}\text { Borghi-Silva et } \text { al }^{26} \\
2014\end{array}$ & Prospective & HFrEF & 86 & Lower EVP suggests higher disease severity \\
\hline Foreman et $\mathbf{a l}^{25} 2012$ & Prospective & HFrEF & 875 & Ventilatory power was the strongest prognostic factor \\
\hline Bandera et al ${ }^{28} 2014$ & Prospective & HFrEF, HFpEF & 136 & A flat $\Delta \mathrm{VO}_{2} / \Delta \mathrm{WR}$ reflects impaired functional phenotype \\
\hline Lewis et al $^{54} 2008$ & Prospective & HFrEF & 30 & Significant correlation between $\mathrm{VE} / \mathrm{VCO}_{2}$ and $\mathrm{PVR}, \mathrm{RVEF}$ \\
\hline Moore et al ${ }^{55} 2007$ & Prospective & HFrEF, HFpEF & 147 & $\begin{array}{l}\mathrm{VE} / \mathrm{VCO}_{2} \text { slope is significantly higher in patients with SHF } \\
\text { compared with DHF }\end{array}$ \\
\hline Kitte et al ${ }^{56} 2006$ & Prospective & HFrEF, HFpEF & 216 & $\begin{array}{l}\text { Patients with DHF have exercise tolerance between that of } \\
\text { patients with SHF and controls }\end{array}$ \\
\hline Guazzi et al ${ }^{57} 2010$ & Prospective & HFpEF & 22 & $\begin{array}{l}\text { CPX parameters can be used for assessment of the degree of } \\
\text { DD }\end{array}$ \\
\hline
\end{tabular}

SHF-systolic HF, DHF-diastolic HF, DD-diastolic dysfunction, HRrEF-heart failure with reduced ejection fraction, HFpEF-heart failure with preserved ejection fraction 


\section{Figure 2 Suggested algorithm for risk stratification in advanced heart failure}

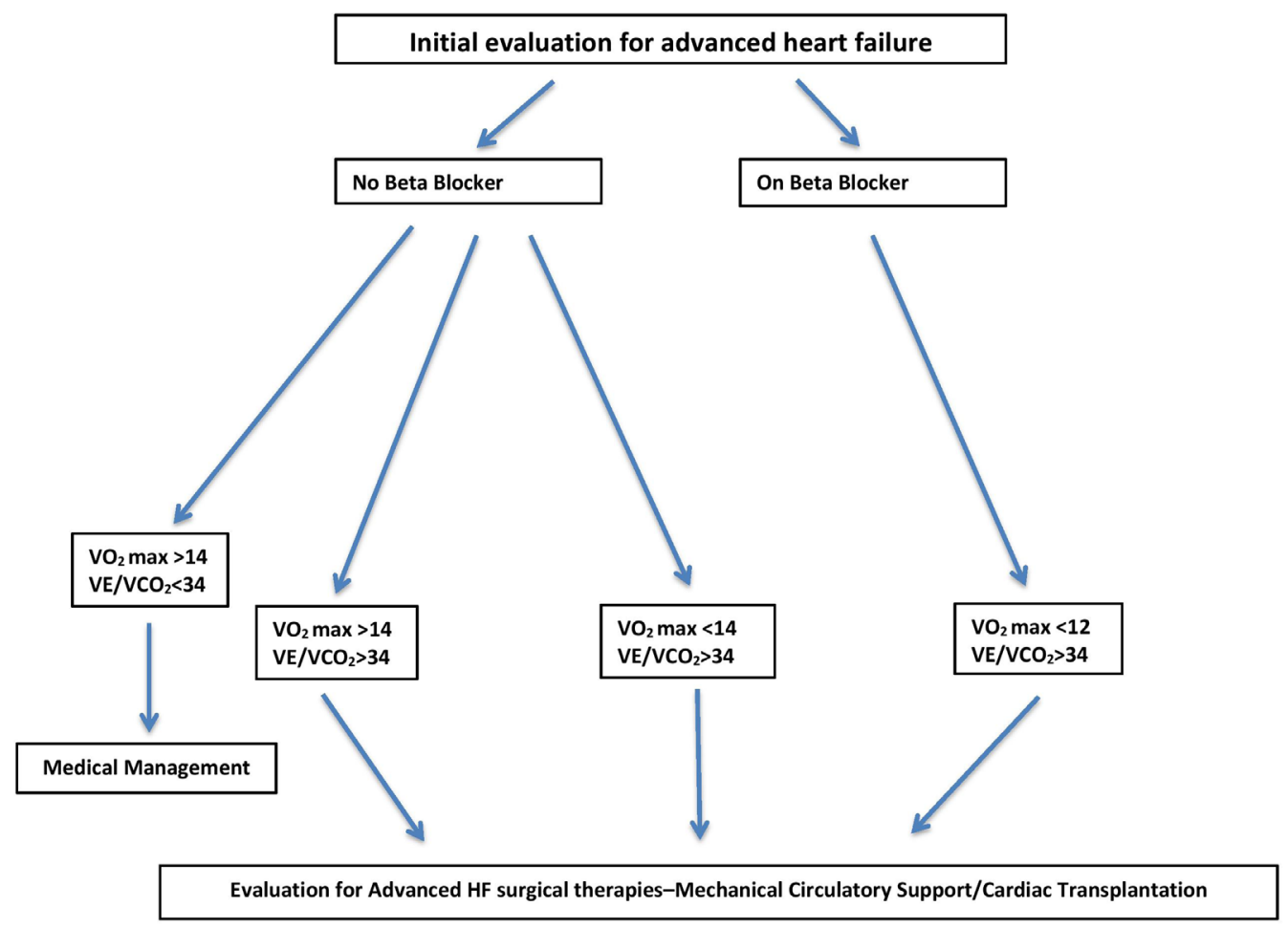

\section{REFERENCES}

1. Mancini DM, Eisen H, Kussmaul W, Mull R, Edmunds LH Jr, Wilson JR. Value of peak exercise oxygen consumption for optimal timing of cardiac transplantation in ambulatory patients with heart failure. Circulation 1991; 83:778-786.

2. Wada O, Asanoi H, Miyagi K, Ishizaka S, Kameyama T, Seto $\mathrm{H}$, Sasayama S. Importance of abnormal lung perfusion in excessive exercise ventilation in chronic heart failure. Am Heart $J$ 1993; 125:790-798.

3. Arena R, Myers J, Guazzi M. Ventilatory abnormalities during exercise in heart failure: a mini review. Curr Resp Med Rev 2007; 3:179-187.

4. Myers J Applications of cardiopulmonary exercise testing in the management of cardiovascular and pulmonary disease. Int $J$ Sports Med 2005; 26(Suppl 1):S49-S55.

5. Rostagno C, Galanti G, Comeglio M, Boddi V, Olivo G, Neri Serneri G. Comparison of different methods of functional evaluation in patients with chronic heart failure. Eur J Heart Fail 2000; 2:273-80.
6. The Criteria Committee of the New York Heart Association. Nomenclature and criteria for diagnosis of diseases of the heart and great vessels. 9th ed Little, Brown \& Co; Boston, Mass: 1994. pp. 253-256.

7. Fleg JL, Pina IL, Balady GJ, Chaitman BR, Fletcher B, Lavie C, Limacher MC, Stein RA, Williams M, Bazzarre T. Assessment of functional capacity in clinical and research applications. An advisory from the Committee on Exercise, Rehabilitation, and Prevention Council on Clinical Cardiology, American Heart Association. Circulation 2000; 102:1591-1597.

8. Myers J, Arena R, Dewey F, Bensimhon D, Abella J, Hsu L, Chase P, Guazzi M, Peberdy MA. A cardiopulmonary exercise testing score for predicting outcomes in patients with heart failure. Am Heart $J$ 2008; 156:1177-83.

9. Genth S, Zotz R, Darius H, Treese N, Sigmund M, Hanrath P, Meyer J. Comparison of NYHA classification with cardiopulmonary function in patients with chronic heart failure. $Z$ Kardiol 1996; 85:428-34.

10. Guazzi M, Labate V, Cahalin LP, Arena R. Cardiopulmonary exercise testing reflects similar pathophysiology and disease se- 
verity in heart failure patients with reduced and preserved ejection fraction. Eur J Prev Cardiol 2014; 21:847-54.

11. Russell SD, Saval MA Robbins JL, Ellestad MH, Gottlieb SS, Handberg EM, Zhou Y Chandler B, and the HF-ACTION Investigators. New York Heart Association functional class predicts exercise parameters in the current era Am Heart J 2009 Oct; 158(4 Suppl): S24-S30.

12. Ashley E, Myers J, Froelicher VF. Exercise testing scores as an example of better decisions through science. Med Sci Sports Exerc 2002; 34: 1391-1398.

13. Swets JA, Dawes RM, Monahan J. Better decisions through science. Sci Am 2000; 283: 82-87.

14. Koopman RJ, Mainous AG3rd. Evaluating multivariate risk scores for clinical decision making. Fam Med 2008; 40: 412-416. 15. Ingle L, Rigby AS, Sloan R, et al. Development of a composite model derived from cardiopulmonary exercise tests to predict mortality risk in patients with mild-to-moderate heart failure. Heart 2014; 100: 781-786.

16. Myers J, Arena R, Dewey F, et al. A cardiopulmonary exercise testing score for predicting outcomes in patients with heart failure. Am Heart $J$ 2008; 156: 1177-1183.

17. Myers J, Oliveira R, Dewey F, et al. Validation of a cardiopulmonary exercise test score in heart failure. Circ Heart Fail 2013; 6: 211-218.

18. Aaronson KD, Schwartz SJ, Chen TM, Wong KL, Goin JE, Mancini DM. Development and prospective validation of a clinical index to predict survival in ambulatory patients referred for cardiac transplant evaluation. Circulation 1997; 95: 2660-2667. 19. Lund LH, Aaronson KD, Mancini DM. Validation of peak exercise oxygen consumption and the Heart Failure Survival Score for serial risk stratification in advanced heart failure. Am J Cardiol 2005; 95: 734-741.

20. Zugck C, Krüger C, Kell R, et al. Risk stratification in middle-aged patients with congestive heart failure: prospective comparison of the Heart Failure Survival Score (HFSS) and a simplified two-variable model. Eur J Heart Fail 2001; 3: 577-585.

21. Guazzi M, Boracchi P, Arena R, et al. Development of a cardiopulmonary exercise prognostic score for optimizing risk stratification in heart failure: the $(\mathrm{P}) \mathrm{e}(\mathrm{R}) \mathrm{i}(\mathrm{O})$ dic $(\mathrm{B})$ reathing during (E)xercise (PROBE) study. $J$ Card Fail 2010; 16: 799-805.

22. Agostoni $\mathrm{P}$, Corrà U, Cattadori G, et al. Metabolic exercise test data combined with cardiac and kidney indexes, the MECKI score: a multiparametric approach to heart failure prognosis. Int J Cardiol 2013; 167: 2710-2718.

23. Ingle L, Rigby, AS, Sloan R, et al. Development of a composite model derived from cardiopulmonary exercise tests to predict mortality risk in patients with mild-to-moderate heart failure. Heart 2014; 100: 781-786.

24. Ingle L. Prognostic value and diagnostic potential of cardiopulmonary exercise testing in patients with chronic heart failure. Eur J Heart Fail 2008; 10: 112-118.
25. Forman, DE, Guazzi, M, Myers J, et al. Ventilatory power: a novel index that enhances prognostic assessment of patients with heart failure. Circ Heart Fail 2012; 5:621-626.

26. Borghi-Silva A, Labate, V, Arena R, et al. Exercise ventilatory power in heart failure patients: Functional phenotypes definition by combining cardiopulmonary exercise testing with stress echocardiography. Int J Cardiol 2014; 176: 1348-1349.

27. Balady GJ, Arena R, Sietsema K, et al. Clinician's guide to cardiopulmonary exercise testing in adults: a scientific statement from the American heart association. Circulation 2010; 122:191225.

28. Bandera $\mathrm{F}$, Generati G, Pellegrino $\mathrm{M}$, et al. Role of right ventricle and dynamic pulmonary hypertension on determining $\Delta \dot{\mathrm{V} O} 2 / \Delta$ Work Rate flattening: insights from cardiopulmonary exercise test combined with exercise echocardiography. Circ Heart Fail 2014;7:782-90.

29. Guazzi M. Abnormalities in cardiopulmonary exercise testing ventilatory parameters in heart failure: pathophysiology and clinical usefulness. Curr Heart Fail Rep 2014;11:80-7

30. Guazzi M, Adams V, Conraads V, et al. EACPR/AHA Scientific Statement. Clinical recommendations for cardio pulmonary exercise testing data assessment in specific patient populations. Circulation 2012; 126:2261-74.

31. Corra U, Giordano A, Bosimini E, et al. Oscillatory ventilation during exercise in patients with chronic heart failure: clinical correlates and prognostic implications. Chest 2002; 121:157280.

32. Corrà U. Exercise oscillatory ventilation in heart failure Int $J$ Cardiol 2016 23. pii: S0167-5273.

33. Corrà U, Agostoni $\mathrm{P}$, Giordano $\mathrm{A}$, et al. The metabolic exercise test data combined with Cardiac And Kidney Indexes (MECKI) score and prognosis in heart failure. A validation study. Int J Cardiol 2016; 203:1067-72.

34. Murphy RM, Shah RV, Malhotra R, et al. Exercise oscillatory ventilation in systolic heart failure: an indicator of impaired hemodynamic response to exercise. Circulation 2011; 124:144251.

35. Olson LJ, Arruda-Olson AM, Somers VK, Scott CG, Johnson BD. Exercise oscillatory ventilation: instability of breathing control associated with advanced heart failure. Chest 2008; 133:47481.

36. Guazzi M, Arena R, Ascione A, Piepoli M, Guazzi MD Exercise oscillatory breathing and increased ventilation to carbon dioxide production slope in heart failure: an unfavorable combination with high prognostic value. Am Heart J 2007; 153:859-67. 37. Guazzi M, Myers J, Peberdy MA, Bensimhon D, Chase P, Arena R. Exercise oscillatory breathing in diastolic heart failure: prevalence and prognostic insights. Eur Heart J 2008;, 29:27519.

38. Arena R, Myers J, Aslam SS, et al. Peak $\dot{\mathrm{VO}}_{2}$ and $\dot{\mathrm{VE}} / \dot{\mathrm{VCO}}_{2}$ slope in patients with heart 
failure: A prognostic comparison. Am Heart J 2004; 147:354-60. 39. Cahalin LP, Arena R, Guazzi M, et al. Inspiratory muscle training in heart disease and heart failure: a review of the literature with a focus on method of training and outcomes. Expert Rev Cardiovasc Ther 2013; 11:161-77.

40. Palange P, Ward SA, Carlsen KH, et al. Recommendations on the use of exercise testing in clinical practice. Eur Respir J 2007; 29:185-209. 123.

41. Cahalin LP, Arena R. Breathing exercises and inspiratory muscle training in heart failure. Heart Fail Clin 2015; 11:149-72. 42. McParland C, Krishnan B, Wang Y, Gallagher CG. Inspiratory muscle weakness and dyspnea in congestive heart failure. Am Rev Respir Dis 1992; 146:467-72.

43. Walsh JT, Andrews R, Johnson P, Phillips L, Cowley AJ, Kinnear WJ Inspiratory muscle endurance in patients with chronic heart failure. Heart 1996; 76:332-6.

44. Mancini DM, Henson D, LaManca J, Levine S. Evidence of reduced respiratory muscle endurance in patients with heart failure. J Am Coll Cardiol 1994; 24:972-81.

45. Meyer FJ, Zugck C, Haas M, et al. Inefficient ventilation and reduced respiratory muscle capacity in congestive heart failure. Basic Res Cardiol 2000; 95:333-42.

46. Meyer FJ, Borst MM, Zugck C, et al. Respiratory muscle dysfunction in congestive heart failure-clinical correlation and prognostic significance. Circulation 200; 103:2153-8.

47. Daganou M, Dimopoulou I, Alivizatos PA, Tzelepis GE. Pulmonary function and respiratory muscle strength in chronic heart failure: comparison between ischaemic and idiopathic dilated cardiomyopathy. Heart 1999; 81:618-20.

48. McIntosh RA, Silberbauer J, Veasey RA, et al. Tissue Doppler-derived contractile reserve is a simple and strong predictor of cardiopulmonary exercise performance across a range of cardiac diseases. Echocardiography 2013; 30:527-33.

49. Okumura $\mathrm{T}$ Hirashiki A, Yamada $\mathrm{S}$, et al. Association between cardiopulmonary exercise and dobutamine stress testing in ambulatory patients with idiopathic dilated cardiomyopathy: a comparison with peak $\mathrm{VO}_{2}$ and $\mathrm{VE} / \mathrm{VCO}_{2}$ slope. Int $J$ Cardiol 2013; 162:234-9.

50. Parthenakis F, Patrianakos A, Nyktari E. Prognostic value of NT-pro BNP, left ventricular inotropic reserve and cardiopulmonary exercise test in patients with non-ischemic dilated cardiomyopathy Int J Cardiol 2011; 147:326-8.

51. Myers J, Ashley E. Dangerous curves: a perspective on exercise, lactate, and the anaerobic threshold. Chest 1997; 111:78795.

52. Myers J, Principles of exercise prescription for patients with chronic heart failure. Heart Fail Rev 2008; 13:61-8.

53. Liu YL, Sun XG, Gao H, Zhang ZY, Feng J, Jiang LQ, Zhang J, Xi JN, Zhou JM, Ge WG. [Preliminary report of using cardiopulmonary exercise testing. guide exercise rehabilitation in patients with chronic heart failure.] Zhongguo Ying Yong Sheng
Li Xue Za Zhi. 2015; 31:374-7. (Chinese)

54. Lewis GD, Shah RV, Pappagianopolas PP, et al. Determinants of ventilatory efficiency in heart failure: the role of right ventricular performance and pulmonary vascular tone. Circ Heart Fail 2008; 1:227-33.

55. Moore B, Brubaker PH, Stewart KP, Kitzman DW. VE/ $\dot{\mathrm{VCO} 2}$ slope in older heart failure patients with normal versus reduced ejection fraction compared with age- matched healthy controls. J Card Fail 2007; 13:259-62.

56. Witte KK, Nikitin NP, Cleland JG, Clark, AL. Excessive breathlessness in patients with diastolic heart failure. Heart 2006; 92:1425-9.

57. Guazzi M, Myers J, Peberdy MA. Cardiopulmonary exercise testing variables reflect the degree of diastolic dysfunction in patients with heart failure normal ejection fraction. $J$ Cardiopulm Rehabil Prev 2010; 30: 165-72.

58. Guazzi M, Arena R, Halle M, et al 2016 Focused Update: Clinical Recommendations for Cardiopulmonary Exercise Testing Data Assessment in Specific Patient Populations. Circ 2016; 133: e694-e711. 